\title{
APPLICATION OF TOPSIS METHOD IN PRIORITIZATION OF HIGHWAY BRIDGES FOR SEISMIC RETROFITTING
}

\author{
Ali YOUSEFI ${ }^{\mathrm{a}}$, Mohd Sanusi S. AHAMAD ${ }^{\mathrm{b}}$, Taksiah A. MAJID ${ }^{\mathrm{a}}$ \\ ${ }^{a}$ Disaster Research Nexus, School of Civil Engineering, Universiti Sains Malaysia, \\ Penang, 14300, Malaysia \\ ${ }^{b}$ School of Civil Engineering, Universiti Sains Malaysia, \\ Penang, 14300, Malaysia
}

Received 13 November 2013; accepted 22 October 2014

\begin{abstract}
The process of bridges seismic retrofitting in the highway network is extremely costly and time consuming. In addition, the constraint on resources prevents the retrofitting of all the bridges at the same time. Besides, the bridges must be prioritized with simultaneous consideration of multiple criteria, including technical and socioeconomic aspect. This study intends to identify the major criteria and consider them simultaneously for prioritization of highway bridges additionally provides an effective technique for weighing these criteria. In this research, TOPSIS (Technique for Order Preference by Similarity to an Ideal Solution) method as a Multi-Criteria Decision-Making (MCDM) model is applied. TOPSIS method enables decision makers to deal with problems involving a large number of alternatives (bridges) and criteria. This methodology reduces multiple alternative (bridge) performances into a single value (ranking score) to facilitate the decision-making process for determination of the most suitable bridges for retrofitting. Suggested criteria include structural vulnerability, seismic hazard, anticipated service life, average daily traffic, interface with other lifelines, alternative routes and bridge importance. Moreover, relative importance (weight) of the criteria is assigned using Analytic Hierarchy Process (AHP) technique. The proposed method is applied to a real case of the Isfahan highway network.
\end{abstract}

Keywords: highway bridges, seismic retrofitting, prioritization, MCDM, TOPSIS.

\section{Introduction}

Natural disasters such as earthquake are of major global concern since these phenomena may produce physical effects on the lifelines such as highway network, consequently reducing disaster risk is an urgent priority for countries (Nielson 2003). Highway networks, which have an important role in the emergency response process, depend on bridges since these networks are often supported and carried by bridges. In other words, bridges as critical components within the highway network, expected to function and remain open immediately following an earthquake. However, many of these bridges are old or were designed without seismic design considerations. As a matter of fact, these bridges are vulnerable from even moderate earthquakes and require some degree of retrofitting for reducing the future social and economic costs in areas with the potential earthquake hazard (JICA 2000; Viera et al. 2000). The observed performance of retrofitted bridges in the past earthquakes indicates that the seismic retrofit of bridges is one of the most cost-effective and efficient mitigation methods. In fact, all bridges that had been retrofitted adequately had minor damage and remained in service. On the other hand, the limitations of resources do not allow the accomplishment of retrofitting for all the bridges simultaneously 
and they must be prioritized before any retrofitting program. In summary, the critical issue in retrofitting program is not lack of technical design and standard or practical issues instead, prioritization methods are required to be improved. For instance, five out of seven bridges that collapsed in the Northridge earthquake (1994) had been scheduled as requiring retrofit, and two other bridges had been identified as not requiring retrofit in the first stage (Housner, Thiel Jr 1995; Yashinsky, Karshenas 2003).

Many methodologies have been studied and proposed to establish policies for more efficient seismic retrofitting program. In some approaches, the highway bridges are ranked in terms of single technical criterion (e.g. vulnerability or seismicity). Briefly, such approaches do not consider multiple criteria, hence bridges in the worst condition or performance are given the highest priority for retrofitting. For instance, in 1993, a report entitled "Prioritization of State Bridges for Seismic Retrofit" was released to prioritize bridges for seismic retrofitting. This report provided a ranking of bridges from the most vulnerable to least vulnerable (Hill 1993). Reiter (1990) and Kramer (1996) considered the probability of collapse during the remaining life of the bridge. They used probabilistic method to determine probability of collapse and to prioritize bridges so that if the collapse probability is high, the bridge is seismically deficient and the bridge is given higher priority for seismic retrofitting.

Some other studies have considered more than a single criterion for prioritization of bridges. In these studies, ranking of bridges is made based on multiple criteria including technical and socioeconomic attribute (e.g. bridge importance and interface with other lifelines) (Liu, Frangopol 2005). Such methods develop a seismic rating system and after that, use the results of this rating to prioritize the bridges. In other words, the result of the bridge ranking is modified using socioeconomic criteria in a subjective way. For example, Federal Highway Administration (FHWA) has issued three editions of retrofit manual for highway bridges FHWA $(1983,1995,2006)$. In 1983, the FHWA published general guidelines for preliminary screening and prioritizing of highway bridges for seismic retrofitting. Seismic ranking of bridges established under these guidelines considered three main factors, including, vulnerability, seismicity and importance. In FHWA (1983), the seismic ranking is a combination of these individuals ranking with weighing factors. The 1983 retrofit guideline (FHWA 1983) was updated in a new manual titled "Seismic Retrofitting Manual for Highway Bridges" (FHWA 1995) which was conceptually similar to FHWA (1983) but described procedures for preliminary screening of bridges and also two approaches for detailed evaluation. "Seismic Retrofitting Manual for Highway Bridges: Part 1-Bridges" (FHWA 2006) which is a replacement for FHWA (1995) contains preliminary screening process, identifying and prioritization procedures for bridges that need to be evaluated for seismic retrofitting. FHWA $(1995,2006)$ take into account technical criteria such as seismic hazards and structural vulnerability to rank the bridges and then use socioeconomic criteria for retrofitting the list of bridges. In other words, proposed methods often imply a considerable degree of subjectivity and common sense for prioritizing and selecting of bridges. In brief, in such approaches, engineering judgment is the final word, though the rating system is used to aim decision makers in prioritizing procedure.

In recent years, Multi Criteria Decision Making (MCDM), as an important component of decision support system, has been of major aids for decision makers significantly to prioritize alternatives and to identify the best solution. MCDM methods have been used in different fields, for instance the selection of seismic upgrading strategies (Caterino et al. 2008), the resource allocation planning (Opricovic 2009), locating a special facility (Queiruga et al. 2008) and material selection (Shanian, Savadogo 2009). The main aim of an MCDM analysis is to reduce multiple alternative performances into a single value to facilitate the decision making process. Hence, the heart piece of any MCDM method is the aggregation procedure. For this reason, the known MCDM methods differ in the way the alternative performances are aggregated.

This study demonstrates the applicability of TOPSIS method for prioritization of bridges in the highway network. This research intends to identify the major engineering and socioeconomic criteria and consider them simultaneously for prioritization of highway bridges and also provides an effective technique for weighing these criteria. TOPSIS method reduces multitude bridge performances into a single value (ranking score) to facilitate the decision-making process for determination of the most suitable choices. Furthermore, this method enables decision makers to deal with prioritization problems involving a large number of bridges and criteria and in the decision-making process for resource allocation. Suggested criteria include structural vulnerability, seismic hazard, anticipated service 
life, average daily traffic, interface with other lifelines, alternative routes and bridge importance. Relative importance (weight) of the criteria is assigned using Analytic Hierarchy Process (AHP) technique. In summary, TOPSIS method is a rapid, straightforward and transparent method that produces a clear priority list almost without requiring the decision maker intervention.

\section{TOPSIS method}

TOPSIS (Technique for Order Preference by Similarity to an Ideal Solution) as a Multi Criteria Decision Making (MCDM) model introduced by Hwang and Yoon (1981). In MCDM problems, the decision makers are faced with a set of alternatives and various kinds of criteria that each criterion has different importance. Therefore, multi-criteria analysis assists decision makers to consider multiple criteria for a large number of alternatives simultaneously. In other words, MCDM analysis aids the decision makers to take better decisions and select the best possible alternative(s) between existing candidates in terms of various criteria. MCDM procedure is divided into engineering and managerial levels. In the engineering level, alternatives are identified and decision analysis is implemented while in the managerial level the final alternative(s) proposed by the engineering level is accepted or rejected (Amiri et al. 2011; Sánchez-Silva 2005).

TOPSIS is an ideal point method that order the alternatives based on closeness to the positive-ideal solution and distance from the negative-ideal solution. This method is rational, intuitive and relatively simple to understand, moreover it does not have strict assumptions of the other MCDM models and produces a cardinal value (Srdjevic et al. 2004). In the following, the general steps of TOPSIS method including alternative selection, establishing evaluation criteria, weighting the evaluation criteria, normalizing the criteria value, ranking and prioritization of alternatives are discussed.

\subsection{Alternatives selection}

Alternatives (herein referred to bridges) represent the different candidates to the decision maker, which are supposed to be evaluated, prioritized and eventually chosen. In this study, conventional highway bridges carrying vehicular traffic (longer than 6 meters, and with spans not exceeding 150 meters) have been considered as alternatives. The Isfahan highway network was chosen as a case study and analysis was carried out on 15 bridges of this network. The city of Isfahan is located in central Iran and in regions of moderate seismic hazard, according to the Iranian seismic code and earthquake hazard map. In this study, the alternatives (bridges) are indicated by $B_{i}(i=1,2, \ldots, 15)$.

\subsection{Establishing evaluation criteria}

Criteria are qualitative or quantitative properties that the performance of the bridges is evaluated according them. In this study, the evaluation of bridges is carried out in terms of some technical and socioeconomic criteria however, each criterion has a relative importance in respect to the other criteria (Caterino et al. 2009; Opricovic, Tzeng 2004). Structural vulnerability, seismic hazard, anticipated service life, average daily traffic, interface with other lifelines, alternative routes and bridge importance have been considered as evaluation criteria in this study.

- Structural Vulnerability (SV)

Structural vulnerability describes the performance and the level of damage to the bridge during an earthquake. Structural vulnerability is one of the most important factors in evaluation of bridges for prioritization. Structural vulnerability depends on the characteristics of the bridge that reflects the structural properties and the physical condition of the bridge. In brief, bridges in poor physical condition are more vulnerable and they are given a higher priority for seismic retrofitting and vice versa (Kawashima, Unjoh 1990). The overall vulnerability of the bridge is determined by estimating vulnerability of critical components of the bridge using visual inspection and considerable engineering judgment (FHWA 2006). This rating ranges from one (failed condition) to nine (excellent) (Markow, Hyman 2009).

\section{- Seismic Hazard (SH)}

Seismic hazard is a function of two factors, the intensity of ground shaking and soil amplification that they represent the seismicity of a region and the geology characteristic of the bridge site, respectively. Hence, to measure the seismic hazard, the peak ground acceleration (PGA) in rock below the bridge site (A) is defined then, it is modified by the site coefficient (S) for soil amplification effects. The seismic hazard is defined as shown by Equation (1).

$$
S H=A \times S,
$$

where $A$ is acceleration coefficient and S is site coefficient. These two factors are treated following. 
The acceleration coefficient (A) is the PGA expected at the rock below the bridge site that has a $15 \%$ probability of exceedance within the design life assumed of the bridge (75 years) which corresponds to approximately $10 \%$ probability of exceedance in the 50 years. The details of different seismic zones can be obtained from microzonation map for each zone. Table 1 shows the acceleration coefficient (A) based on a microzonation map of Iran (IIEES 2012).

Table 1. Acceleration coefficient (A) (IIEES 2012)

\begin{tabular}{|c|l|c|}
\hline Region & \multicolumn{1}{|c|}{ Description } & $\begin{array}{c}\text { Acceleration } \\
\text { Coefficient }\end{array}$ \\
\hline 1 & Very high seismic relative hazard & 0.35 \\
\hline 2 & High seismic relative hazard & 0.30 \\
\hline 3 & Intermediate seismic relative hazard & 0.25 \\
\hline 4 & Low seismic relative hazard & 0.20 \\
\hline
\end{tabular}

Site coefficient (S) represents the geotechnical and ground conditions of the bridge site. Motions at the surface may be considerably greater than in the rock below the site due to amplification of the first ground shaking. To consider the soil amplification, the PGA is modified by the site coefficient (S) which is established from Table 2 (FHWA 1995).

Table 2. Site coefficient (S) (FHWA 1995)

\begin{tabular}{|c|c|}
\hline Soil Profile Type & Site Coefficient \\
\hline I & 1.0 \\
\hline II & 1.2 \\
\hline III & 1.5 \\
\hline IV & 2.0 \\
\hline
\end{tabular}

- Anticipated Service Life (SL)

Another factor that should be considered for bridge evaluation is "anticipated service life" which is the number of years a bridge is expected to remain in use. Anticipated service life is determined by subtracting the age of the bridge from the assumed service life (which is 75 years for new bridges).

\section{- Average Daily Traffic (DT)}

Average daily traffic represents the average traffic volume of people or vehicles that travel on the bridge. Traffic level describes the number of people that are exposed to seismic hazards and the potential impact of an earthquake to the public safety (Valenzuela et al. 2010).

\section{- Interference with other Lifelines (IL)}

This criterion shows the number of other lifelines and utilities that may be carried on bridges since bridges often support a combination of lifelines and utilities. For instance, the cells of cast-in-place box girders and the space between pre-manufactured girders often used to carry other utilities such as gas lines, high-pressure water lines, and electrical or telephone cables.

\section{- Alternatives Routes (AR)}

The alternative route or detour nearby the bridge that permits traffic flow after an earthquake is an important issue when deciding for priority of bridges. To illustrate, Bridges located in highway network with high redundancy and with alternative routes are assigned a lower priority for retrofitting and vice versa. The bridge rating (based on available alternative routes) is assigned according to Table 3 .

\section{- Bridge Importance (BI)}

This parameter represents the strategic importance of the bridge in the highway network. It is determined according to other factors, including social, financial and survival requirements (e.g. bridge's value to the community, and the time and budget required for repair or replacement). In this study, three catego-

Table 3. Alternatives routes rating (Valenzuela et al. 2010)

\begin{tabular}{|l|l|c|}
\hline \multicolumn{1}{|c|}{ Type of detour } & \multicolumn{1}{|c|}{ Description } & Rating \\
\hline Parallel Bridge & There exists an alternative bridge nearby that permits traffic flow with low disruptions and delays. & 1 \\
\hline $\begin{array}{l}\text { Parallel Bridge } \\
\text { or Road }\end{array}$ & $\begin{array}{l}\text { There exist an alternative bridge or route nearby with a similar standard that permit traffic flow } \\
\text { with minor congestion on the bridge. The travel distance is similar without changing the time } \\
\text { travel and road user costs. }\end{array}$ & 2 \\
\hline Long Detour & There exist an alternative route increases travel time and road user costs with minor congestion. & 3 \\
\hline $\begin{array}{l}\text { Very Long } \\
\text { Detour }\end{array}$ & $\begin{array}{l}\text { There exists an alternative route with higher than } 10 \mathrm{~km} \text { of length and congestion on the bridge. } \\
\text { Its standard is lower than the main route. }\end{array}$ & 4 \\
\hline $\begin{array}{l}\text { Without } \\
\text { Detours }\end{array}$ & There are no alternative routes. & 5 \\
\hline
\end{tabular}


ries were specified for bridge importance, containing "strategic" (extremely important), "critical" (important) and "standard".

1. Strategic: Bridge that its fail would impose catastrophic impact on a region, or bridge that is formally defined as strategic by a local plane (or the bridge crossing strategic route).

2. Critical: Bridge that is required to provide secondary life safety and must be remaining in service following an earthquake. As well as a bridge, that is part of a critical lifeline route or critical link in the security and/or defense roadway network.

3. Standard: All other bridges are classified as standard.

\subsection{Weighting the evaluation criteria}

Once the evaluation criteria are identified, the next step is to assign the weight of each criterion. Weight of criteria indicates their relative and the overall importance in respect to the other criteria therefore, it is an important part of the analysis. Since the criteria are expressed in different measurement units, it is difficult to determine the values of such weights. In this regards, rationalizing and using proven elicitation techniques help to get the values of the weights. The weights are determined according to expert judgments when they have a good knowledge about the criteria, in terms of value of criteria and the relationships between them (Opricovic, Tzeng 2004). In this study, AHP method, which is a well-structured method and is based on underlying statistical theory, was accomplished for determination of the criteria weight. The initial developments of AHP theory were done by Thomas Saaty in 1971 (Saaty, Vargas 1994). The AHP method involves making pairwise comparisons amongst all the criteria which represents the judgments of the experts with respect to each criterion importance over another criterion (Malczewski 2006). The comparison matrix is an $\mathrm{n} \times \mathrm{n}$ matrix filled through questionnaire surveys by individual experts. In the questionnaire, the experts were asked to compare each two criteria with answering the questions: "Which of the two is more important, and how much more important is it than the other?" In order to quantify the measure of dominance a 1 to 9 underling scale was used which describes the relative preferences of the experts for two criteria. For example, in pairwise comparison of "Structural Vulnerability" and "Alternative Routs", if "Structural Vulnerability" is strongly important than "Alternative Routs", the expert may choose the value of five. Table 4 shows the scale of importance for pairwise comparison as used in AHP (Ozbek et al. 2012).

The results of the pairwise comparisons are placed within a positive reciprocal matrix (A).Once the comparison matrix (A) is formed, the weight of the criteria is calculated and elicited by normalizing the eigenvector $(\omega)$ of comparison matrix (A) through Equation (2) (Carnero 2006; Sinuany-Stern et al. 2000).

$$
w_{j}=\frac{\omega_{j}}{\sum_{j=1}^{n} \omega_{j}},
$$

where $\omega$ is the normalized eigenvector of matrix $A$ and $w_{j}$ is the weight of criterion $j$. Through the normalization, the sum of the entries in eigenvector to be equal to one and the weights are determined. AHP method also measures the consistency of the pairwise comparison matrix to identify how consistent the participant was in making comparisons. If the consistency ratio (C.R.) is not exceeded than 0.10 (C.R. $\leq 0.10$ ), the participants' responses in pairwise comparisons are considered to be relatively consistent (Ozbek et al. 2012). Table 5 presents the weights of considered criteria $\left(w_{j}\right)$.

Table 5. Criteria weighting $\left(w_{j}\right)$

\begin{tabular}{|l|l|}
\hline \multicolumn{1}{|c|}{ Criteria } & Weight \\
\hline Structural Vulnerability (SV) & 0.405 \\
\hline Seismic Hazard (SH) & 0.300 \\
\hline Anticipated Service life (SL) & 0.137 \\
\hline Average Daily Traffic (DT) & 0.070 \\
\hline Interface with Other Lifelines (IL) & 0.037 \\
\hline Alternative Routes (AR) & 0.025 \\
\hline Bridge Importance (BI) & 0.025 \\
\hline
\end{tabular}

Table 4. Scale of importance for pairwise comparison

\begin{tabular}{|c|c|c|c|c|c|c|c|c|c|c|c|c|c|c|c|c|c|c|}
\hline \multirow[b]{2}{*}{$\begin{array}{c}\text { Criterion } \\
1\end{array}$} & \multirow{2}{*}{$\begin{array}{c}\text { Extremely } \\
9\end{array}$} & \multicolumn{2}{|c|}{$\begin{array}{c}\text { Very } \\
\text { strongly }\end{array}$} & \multicolumn{2}{|c|}{ Strongly } & \multicolumn{2}{|c|}{ Moderately } & \multicolumn{3}{|c|}{$\begin{array}{l}\text { Equally } \\
\text { important }\end{array}$} & \multicolumn{2}{|c|}{ Moderately } & \multicolumn{2}{|c|}{ Strongly } & \multicolumn{2}{|c|}{$\begin{array}{c}\text { Very } \\
\text { strongly }\end{array}$} & \multirow{2}{*}{\begin{tabular}{|c|} 
Extremely \\
9
\end{tabular}} & \multirow[b]{2}{*}{$\begin{array}{c}\text { Criterion } \\
2\end{array}$} \\
\hline & & 8 & 7 & 6 & 5 & 4 & 3 & 2 & 1 & 2 & 3 & 4 & 5 & 6 & 7 & 8 & & \\
\hline
\end{tabular}




\subsection{Analysis and evaluation matrix}

MCDM problems involving a set of alternatives and criteria required to be expressed in a matrix format that allows systematically identifies and analyses of relationships between the large amounts of information. The decision matrix is defined as a $m \times n$ matrix ( $m$ alternatives and $n$ criteria) in which the element $f_{i j}(i=$ $1,2,3, \ldots, \mathrm{m}$ and $j=1,2,3, \ldots, n)$ indicates the value of the alternative $i$ when it is evaluated in the terms of the criterion $j$. In other words, the performance of alternative $i$ with respects to criterion $j$ is exhibited by element $f_{i j}$ in the decision matrix (Mysiak 2004). Table 6 shows the decision matrix (the alternatives (bridges) on the left side and the criteria at the top of the matrix).

Table 6. Decision matrix

\begin{tabular}{|c|c|c|c|c|c|c|c|}
\hline \multirow{2}{*}{ Bridges } & \multicolumn{7}{|c|}{ Criteria } \\
\cline { 2 - 8 } & SV & SH & SL & DT & IL & AR & BI \\
\hline $\mathrm{B}_{1}$ & 1 & 0.250 & 72 & 18304 & 2 & 3 & 2 \\
\hline $\mathrm{B}_{2}$ & 8 & 0.500 & 25 & 15437 & 2 & 3 & 2 \\
\hline $\mathrm{B}_{3}$ & 2 & 0.300 & 68 & 35538 & 3 & 1 & 1 \\
\hline $\mathrm{B}_{4}$ & 5 & 0.400 & 46 & 26435 & 2 & 3 & 1 \\
\hline $\mathrm{B}_{5}$ & 7 & 0.500 & 33 & 27689 & 3 & 2 & 2 \\
\hline $\mathrm{B}_{6}$ & 4 & 0.240 & 54 & 19876 & 1 & 3 & 2 \\
\hline $\mathrm{B}_{7}$ & 3 & 0.400 & 60 & 34230 & 3 & 1 & 1 \\
\hline $\mathrm{B}_{8}$ & 2 & 0.300 & 68 & 9873 & 1 & 4 & 3 \\
\hline $\mathrm{B}_{9}$ & 6 & 0.300 & 40 & 20759 & 2 & 3 & 2 \\
\hline $\mathrm{B}_{10}$ & 5 & 0.375 & 45 & 23784 & 3 & 2 & 1 \\
\hline $\mathrm{B}_{11}$ & 6 & 0.300 & 38 & 20483 & 2 & 3 & 2 \\
\hline $\mathrm{B}_{12}$ & 4 & 0.300 & 52 & 26463 & 3 & 3 & 2 \\
\hline $\mathrm{B}_{13}$ & 2 & 0.375 & 68 & 23970 & 2 & 3 & 2 \\
\hline $\mathrm{B}_{14}$ & 3 & 0.400 & 62 & 24982 & 1 & 3 & 2 \\
\hline $\mathrm{B}_{15}$ & 3 & 0.375 & 63 & 10242 & 2 & 4 & 3 \\
\hline
\end{tabular}

\subsection{Normalizing the criteria values}

Generally, there are two kinds of criteria, the benefit type (the higher value and rating is better) and the cost type (the lower value and rating is better). For example, the criterion "anticipated service life" is benefit type, while "structural vulnerability" is cost type. Moreover, criteria may be associated with different units of measurement and scales. Consequently, the bridges' performances concerning different criteria and different measurement units have to be made comparable. Hence, to obtain comparable scales and eliminate computational problems, the criteria values have to be normalized and transformed into a uniform scale $(0,1]$ with dimensionless units (Azar 2000; Mysiak 2004). Vector normalization method is utilized in TOPSIS approach to normalize the criteria values. The normalized decision matrix is calculated by Equation (3) for all the values $f_{i j}$ exhibited in the original matrix.

$$
r_{i j}=f_{i j} / \sqrt{\sum_{i=1}^{m} f_{i j}^{2}},
$$

where $r_{i j}$ is the normalized value of $f_{i j}$ and $f_{i j}$ is the response of bridge $i$ on criterion $j$.

\subsection{Ranking and prioritization}

TOPSIS technique is based on the concept of closeness to the ideal solutions that is measured in Euclidean distance. In other words, alternatives are proposed as best options, which are within proximity to the positive-ideal solution and the remoteness from the negative-ideal solution simultaneously or reverse (Zanakis et al. 1998). The ideal solution is the collection of ideal performance values in all criteria (Shanian, Savadogo 2009). TOPSIS method involves following steps for scoring and prioritization of bridges in sequence.

1. Calculate weighted normalized decision matrix $\left(v_{i j}\right)$. It is obtained by multiplying the weight of the criterion $\left(w_{j}\right)$ with the normalized matrix $\left(r_{i j}\right)$ as denoted in Equation (4). Table 7 shows the weighted normalized decision matrix.

$$
v_{i j}=w_{j} \times r_{i j} .
$$

Table 7. Weighted normalized decision matrix $\left(\mathrm{v}_{\mathrm{ij}}\right)$

\begin{tabular}{|c|c|c|c|c|c|c|c|}
\hline \multirow{2}{*}{ Bridges } & \multicolumn{7}{|c|}{ Criteria } \\
\cline { 2 - 8 } & $\mathrm{SV}$ & $\mathrm{SH}$ & $\mathrm{SL}$ & $\mathrm{DT}$ & $\mathrm{IL}$ & $\mathrm{AR}$ & $\mathrm{BI}$ \\
\hline $\mathrm{B}_{1}$ & 0.0234 & 0.0534 & 0.0475 & 0.0140 & 0.0092 & 0.0081 & 0.0079 \\
\hline $\mathrm{B}_{2}$ & 0.1872 & 0.1068 & 0.0165 & 0.0118 & 0.0092 & 0.0081 & 0.0079 \\
\hline $\mathrm{B}_{3}$ & 0.0468 & 0.0641 & 0.0449 & 0.0272 & 0.0138 & 0.0027 & 0.0039 \\
\hline $\mathrm{B}_{4}$ & 0.1170 & 0.0855 & 0.0304 & 0.0202 & 0.0092 & 0.0081 & 0.0039 \\
\hline $\mathrm{B}_{5}$ & 0.1638 & 0.1068 & 0.0218 & 0.0212 & 0.0138 & 0.0054 & 0.0079 \\
\hline $\mathrm{B}_{6}$ & 0.0936 & 0.0513 & 0.0356 & 0.0152 & 0.0046 & 0.0081 & 0.0079 \\
\hline $\mathrm{B}_{7}$ & 0.0702 & 0.0855 & 0.0396 & 0.0262 & 0.0138 & 0.0027 & 0.0039 \\
\hline $\mathrm{B}_{8}$ & 0.0468 & 0.0641 & 0.0449 & 0.0075 & 0.0046 & 0.0108 & 0.0118 \\
\hline $\mathrm{B}_{9}$ & 0.1404 & 0.0641 & 0.0264 & 0.0159 & 0.0092 & 0.0081 & 0.0079 \\
\hline $\mathrm{B}_{10}$ & 0.1170 & 0.0801 & 0.0297 & 0.0182 & 0.0138 & 0.0054 & 0.0039 \\
\hline $\mathrm{B}_{11}$ & 0.1404 & 0.0641 & 0.0251 & 0.0157 & 0.0092 & 0.0081 & 0.0079 \\
\hline $\mathrm{B}_{12}$ & 0.0936 & 0.0641 & 0.0343 & 0.0202 & 0.0138 & 0.0081 & 0.0079 \\
\hline $\mathrm{B}_{13}$ & 0.0468 & 0.0801 & 0.0449 & 0.0183 & 0.0092 & 0.0081 & 0.0079 \\
\hline $\mathrm{B}_{14}$ & 0.0702 & 0.0855 & 0.0409 & 0.0191 & 0.0046 & 0.0081 & 0.0079 \\
\hline $\mathrm{B}_{15}$ & 0.0702 & 0.0801 & 0.0416 & 0.0078 & 0.0092 & 0.0108 & 0.0118 \\
\hline & & & & & & & \\
\hline
\end{tabular}


2. Identify positive-ideal and negative-ideal solutions. The positive-ideal solution $\left(\mathrm{B}^{*}\right)$ is obtained from the best performance value of each criterion as denoted in Equation (5). While the negative-ideal solution $\left(\mathrm{B}^{-}\right)$is obtained from the worst performance value as denoted in Equation (6).

$$
\begin{aligned}
B^{*} & =\left\{v_{1}^{*}, v_{2}^{*}, \ldots, v_{i}^{*}, \ldots, v_{n}^{*}\right\}, \\
B^{-} & =\left\{v_{1}^{-}, v_{2}^{-}, \ldots, v_{i}^{-}, \ldots, v_{n}^{-}\right\},
\end{aligned}
$$

where $v^{*}$ is the best value and $v^{-}$is the worst value for criterion $\mathrm{j}$ among all the bridges.

The positive-ideal solutions $\left(B^{*}\right)$ and negative-ideal solutions $\left(B^{-}\right)$for each criterion is shown in Table 8.

Table 8. Positive-ideal $\left(B^{*}\right)$ and negative-ideal $\left(B^{-}\right)$solutions

\begin{tabular}{|c|c|c|c|c|c|c|c|}
\hline Solution & SV & SH & SL & DT & IL & AR & BI \\
\hline$B^{-}$ & 0.0234 & 0.0513 & 0.0475 & 0.0075 & 0.0046 & 0.0027 & 0.0118 \\
\hline$B^{*}$ & 0.1872 & 0.1068 & 0.0165 & 0.0272 & 0.0138 & 0.0108 & 0.0039 \\
\hline
\end{tabular}

3. Calculate the Euclidean distance from ideal solutions. The closeness of each alternative to the positive-ideal solution can be measured by the $n$-dimensional Euclidean distance using Equation (7):

$$
S_{i}^{*}=\sqrt{\sum_{j=1}^{n}\left(v_{i j}-v_{j}^{*}\right)^{2}} .
$$

Similarly, Equation (8) indicates the separation of each alternative from the negative-ideal solution.

$$
S_{i}^{-}=\sqrt{\sum_{j=1}^{n}\left(v_{i j}-v_{j}^{-}\right)^{2}} .
$$

4. Calculate similarity indexes $\left(C_{i}\right)$. Similarity index $\left(C_{i}\right)$ implies the relative closeness to the ideal solution and it will be used for the prioritization of bridges. It is obtained by Equation (9) and ranges in the interval $(0,1]$.

$$
C_{i}=S_{i}^{-} /\left(S_{i}^{*}+S_{i}^{-}\right) .
$$

5. Prioritizing the bridges. The priority list is made with respect to the $C_{i}$ values in ascending order.

\section{Results and discussion}

As it was mentioned, TOPSIS method is based on aggregating function that representing the closeness to ideal solutions and the remoteness from the negativeideal solution simultaneously or reverse (Chu et al. 2007; Tzeng et al. 2005). In this study, the "similarity index" was defined by combining the proximity to the negative-ideal solution and the remoteness of the positive-ideal solution in order to determine the best-preferred bridges. Bridges with the lowest similarity index $\left(C_{i}\right)$ are given higher priorities because they have the shortest distance from the negative-ideal solution and the longest distance from the positive-ideal solution. Table 9 shows the obtained results, including the values $\mathrm{S}^{*}, \mathrm{~S}^{-}$and $\mathrm{C}_{\mathrm{i}}$ for each bridge.

From Table 9, it is observed that TOPSIS method represents bridges $B_{2}, B_{5}, B_{11}, B_{9}$ and $B_{4}$ as high priority ones for seismic retrofitting due to their lower final scores. These bridges can be considered the best choice because of the minimum distance to the negative-ideal solution and longest distance to the positive-ideal solution. Considering of first five bridges $\left(B_{2}, B_{5}, B_{11}, B_{9}\right.$ and $\mathrm{B}_{4}$ ) shows that not only these bridges have overall low scores but also according to the decision matrix (Table 6), they have individual low criteria values compared to other bridges. For instant, these bridges are most vulnerable bridges in the highway network and they have the lowest performance value between all the bridges. In a similar way, bridges $\mathrm{B}_{1}, \mathrm{~B}_{8}, \mathrm{~B}_{3}, \mathrm{~B}_{13}$ and $B_{15}$ that have the highest ranking score are presented as lowest priority bridges. In summary, the characteristics of the selected bridges $\left(B_{2}, B_{5}, B_{11}, B_{9}\right.$ and $\left.B_{4}\right)$ with respect to engineering and socioeconomic criteria encourage us to select them as the best choices.

Table 9. $S^{*}, S^{-}$and $C_{i}$ according to TOPSIS method

\begin{tabular}{|c|c|c|c|c|}
\hline Bridges & $\mathrm{S}^{*}$ & $S^{-}$ & $\mathrm{C}_{\mathrm{i}}$ & Priority \\
\hline $\mathrm{B}_{1}$ & 0.0106 & 0.2468 & 0.95885 & 15 \\
\hline $\mathrm{B}_{2}$ & 0.1759 & 0.0186 & 0.09558 & 1 \\
\hline $\mathrm{B}_{3}$ & 0.0354 & 0.2240 & 0.86366 & 13 \\
\hline $\mathrm{B}_{4}$ & 0.1024 & 0.1392 & 0.57612 & 5 \\
\hline $\mathrm{B}_{5}$ & 0.1541 & 0.0781 & 0.33635 & 2 \\
\hline $\mathrm{B}_{6}$ & 0.0719 & 0.1766 & 0.71057 & 8 \\
\hline $\mathrm{B}_{7}$ & 0.0626 & 0.1937 & 0.75585 & 9 \\
\hline $\mathrm{B}_{8}$ & 0.0280 & 0.2245 & 0.88910 & 14 \\
\hline $\mathrm{B}_{9}$ & 0.1201 & 0.1190 & 0.49754 & 4 \\
\hline $\mathrm{B}_{10}$ & 0.1009 & 0.1384 & 0.57835 & 6 \\
\hline $\mathrm{B}_{11}$ & 0.1204 & 0.1133 & 0.48489 & 3 \\
\hline $\mathrm{B}_{12}$ & 0.0745 & 0.1693 & 0.69434 & 7 \\
\hline $\mathrm{B}_{13}$ & 0.0396 & 0.2213 & 0.84828 & 12 \\
\hline $\mathrm{B}_{14}$ & 0.0598 & 0.1967 & 0.76675 & 10 \\
\hline $\mathrm{B}_{15}$ & 0.0561 & 0.2000 & 0.78109 & 11 \\
\hline & & & & \\
\hline
\end{tabular}


However, it is the first time that all the major criteria are considered simultaneously, the studies such as Bana e Costa et al. (2008) and Kuprenas et al. (1998) have shown the similar weight for considered criteria that validate the consistency of the weight obtained in this study. In addition, the Consistency Ratio (CR = 0.072) of the pairwise comparison matrix indicates a high-level of consistency for the weighting of criteria. Based on the results obtained, it is observed that the final ranking of each bridge, which is determined by measuring its Euclidean distance associated with the performance indices, is highly sensitive to weights. The other point is that the effect of each criterion cannot be considered alone and must always be seen as a trade-off with respect to the other criteria. The bridges found high priority in the prioritized list are should be subjected to the detailed evaluation before retrofitting is undertaken on them.

\section{Conclusions}

Generally, in seismic retrofitting procedure, major technical criteria such as vulnerability or seismicity are considered for prioritization of bridges. However, other important aspects like socioeconomic criteria have been considered in some studies, they are just used in modification of the priority list in a subjective way. In this study, seven engineering and socioeconomic criteria, including structural vulnerability, seismic hazard, anticipated service life, average daily traffic, interface with other lifelines, alternative routes and bridge importance were identified and considered simultaneously. With respect to the obtained weight of criteria, it can be concluded that the structural vulnerability and seismic hazard criteria play an essential role in the prioritization of bridges for retrofitting. Instead, those criteria whose weighted coefficients are of low value have no major effect on the final ranking of bridges.

In the present study, the applicability of TOPSIS method in prioritization of highway bridges was investigated. This method has this capability to deal with the various kinds of criteria and large number of bridges involved in a decision problem simultaneously. Moreover, it provides the possibility to add or change some of the criteria. TOPSIS method is an appropriate and effective method for prioritization of bridges since it provides a convenient mathematical model for treating the uncertainty, subjectivity and imprecision. In other words, this method produces a cardinal value and leads to the clear priority list based on final scores and almost without requiring the decision maker's intervention. Utilization of proposed method enables decision makers and authorities to determine the priority of bridges for retrofitting in the network for resource allocation. TOPSIS method is a rapid, straightforward and transparent method, hence it is expected that to be conducted for other components of lifeline networks at regional and national scale.

\section{Acknowledgements}

The authors gratefully acknowledge the Universiti Sains Malaysia (USM) Graduate Assistance scheme for the financial support during the completion of this paper.

\section{References}

Amiri, M.; Ayazi, A.; Olfat, L.; Moradi, J. 2011. Group decision making process for supplier selection with VIKOR under fuzzy circumstance case study: an iranian car parts supplier, International Bulletin of Business Administration 10: 62-75.

Azar, F. S. 2000. Multiattribute decision-making: use of three scoring methods to compare the performance of imaging techniques for breast cancer detection. Technical reports. Paper 119. University of Pensilvania.

Bana e Costa, C. A.; Oliveira, C. S.; Vieira, V. 2008. Prioritization of bridges and tunnels in earthquake risk mitigation using multicriteria decision analysis: application to Lisbon, Omega-International Journal of Management Science 36(3): 442-450. http://dx.doi.org/10.1016/j.omega.2006.05.008

Carnero, M. C. 2006. An evaluation system of the setting up of predictive maintenance programmes, Reliability Engineering \& System Safety 91(8): 945-963.

http://dx.doi.org/10.1016/j.ress.2005.09.003

Caterino, N.; Iervolino, I.; Manfredi, G.; Cosenza, E. 2008. Multi-Criteria Decision Making for seismic retrofitting of RC structures, Journal of Earthquake Engineering 12(4): 555-583. http://dx.doi.org/10.1080/13632460701572872

Caterino, N.; Iervolino, I.; Manfredi, G.; Cosenza, E. 2009. Comparative analysis of Multi-Criteria Decision-Making methods for seismic structural retrofitting, Computer-Aided Civil and Infrastructure Engineering 24(6): 432-445. http://dx.doi.org/10.1111/j.1467-8667.2009.00599.x

Chu, M.-T.; Shyu, J.; Tzeng, G.-H.; Khosla, R. 2007. Comparison among three analytical methods for knowledge communities group-decision analysis, Expert Systems with Applications 33(4): 1011-1024. http://dx.doi.org/10.1016/j.eswa.2006.08.026

Federal Highway Administration (FHWA). 1983. Seismic retrofitting guidelines for highway bridges: earthquake protection of transportation structures, Publication No. FHWARD-83-007, US Department of Transportation, Federal Highway Administration Washington, DC.

Federal Highway Administration (FHWA). 1995. Seismic retrofitting manual for highway bridges, Publication No. FHWA- 
RD-94-052, Federal Highway Administration, US Department of Transportation, McLean, VA.

Federal Highway Administration (FHWA). 2006. Seismic retrofitting manual for highway structures: part 1-bridges, Publication No. FHWA-HRT-06-032. Federal Highway Administration, US Department of Transportation, McLean, VA. Also published as Special Publication, MCEER-06-SP10, Multidisciplinary Center for Earthquake Engineering Research, Buffalo NY.

Hill, C. M. 1993. Prioritization of state bridges for seismic retrofit, Oregon Department of Transportation bridge seismic retrofit prioritization model: final report. Bridge seismic retrofit prioritization model. ODOT bridge seismic retrofit prioritization.

Housner, G. W.; Thiel Jr, C. C. 1995. The continuing challenge: report on the performance of state bridges in the Northridge earthquake, Earthquake Spectra 11(4): 607-636. http://dx.doi.org/10.1193/1.1585829

Hwang, C. L.;Yoon, K. 1981. Multiple attribute decision making: methods and applications: a state-of-the-art survey. Berlin: Springer. http://dx.doi.org/10.1007/978-3-642-48318-9

The International Institute of Earthquake Engineering and Seismology (IIEES) [online], 2012 [cited 01 September 2013]. Available from Internet: http://www.iiees.ac.ir/iiees/English/ index_e.asp

Japan International Cooperation Agency (JICA). 2000. The study on seismic microzoning of the greater Tehran area in the islamic republic of Iran. Final Report to the Government of the Islamic Republic of Iran. 379.

Kawashima, K.; Unjoh, S. 1990. An inspection method of seismically vulnerable existing highway bridges, in Proc. JSCE, Structural Engineering and Earthquake Engineering 416: 143-150.

Kramer, S. L. 1996. Geotechnical earthquake engineering. Pearson Education India.

Kuprenas, J.; Madjidi, F.;Vidaurrazaga, A.; Lim, C. 1998. Seismic retrofit program for Los Angeles bridges, Journal of Infrastructure Systems 4(4): 185-191.

http://dx.doi.org/10.1061/(ASCE)1076-0342(1998)4:4(185)

Liu, M.; Frangopol, D. 2005. Time-dependent bridge network reliability: novel approach, Journal of Structural Engineering 131(2): 329-337.

http://dx.doi.org/10.1061/(ASCE)0733-9445(2005)131:2(329)

Malczewski, J. 2006. GIS-based multicriteria decision analysis: a survey of the literature, International Journal of Geographical Information Science 20(7): 703-726.

http://dx.doi.org/10.1080/13658810600661508

Markow, M.; Hyman, W. 2009. NCHRP synthesis 397: Bridge management systems for transportation agency decision making. Transportation Research Board of the National Academies, Washington, DC.

Mysiak, J. 2004. mDSS Decision methods: NetSyMod [online], [cited 01 September 2013]. Available from Internet: http:// www.netsymod.eu/mdss/mDSS_DECMETH.pdf

Nielson, B. 2003. Bridge seismic fragility-functionality relationships: a requirement for loss estimation in mid-America. Georgia Institute of Technology, Texas.

Opricovic, S. 2009. A compromise solution in water resources planning, Water Resources Management 23(8): 1549-1561. http://dx.doi.org/10.1007/s11269-008-9340-y
Opricovic, S.; Tzeng, G.-H. 2004. Compromise solution by MCDM methods: a comparative analysis of VIKOR and TOPSIS, European Journal of Operational Research 156(2): 445-455. http://dx.doi.org/10.1016/S0377-2217(03)00020-1

Ozbek, M. E.; Clevenger, C. M.; Fillion, A. C. 2012. A quantitative decision-making framework to evaluate environmental commitment tracking systems, Transportation Research Record: Journal of the Transportation Research Board 2270(1): 188-194. http://dx.doi.org/10.3141/2270-22

Queiruga, D.; Walther, G.; González-Benito, J.; Spengler, T. 2008. Evaluation of sites for the location of WEEE recycling plants in Spain, Waste Management 28(1): 181-190. http://dx.doi.org/10.1016/j.wasman.2006.11.001

Reiter, L. 1990. Earthquake hazard analysis: issues and insights. Columbia University Press.

Saaty, T. L.; Vargas, L. G. 1994. Decision making in economic, political, social, and technological environments with the analytic hierarchy process. Rws Publications.

Sánchez-Silva, M., 2005. Risk analysis and the decision-making process in engineering, in Intelligent Knowledge-Based Systems. Springer US, 1361-1393.

Shanian, A.; Savadogo, O. 2009. A material selection of highly sensitive components based on multiple criteria decision analysis, Expert Systems with Applications 36(2, Part 1): 1362-1370. http://dx.doi.org/10.1016/j.eswa.2007.11.052

Sinuany-Stern, Z.; Mehrez, A.; Hadad, Y. 2000. An AHP/DEA methodology for ranking decision making units, International Transactions in Operational Research 7(2): 109-124. http://dx.doi.org/10.1111/j.1475-3995.2000.tb00189.x

Srdjevic, B.; Medeiros, Y.; Faria, A. 2004. An objective multicriteria evaluation of water management scenarios, Water Resources Management 18(1): 35-54. http://dx.doi.org/10.1023/B:WARM.0000015348.88832.52

Tzeng, G.-H.; Lin, C.-W.; Opricovic, S. 2005. Multi-criteria analysis of alternative-fuel buses for public transportation, Energy Policy 33(11): 1373-1383.

http://dx.doi.org/10.1016/j.enpol.2003.12.014

Valenzuela, S.; Solminihac, H. D.; Echaveguren, T. 2010. Proposal of an integrated index for prioritization of bridge maintenance, Journal of Bridge Engineering 15(3): 337-343. http://dx.doi.org/10.1061/(ASCE)BE.1943-5592.0000068

Viera, V.; Oliveira, C. S.; Costa, C. B. 2000. A methodology to evaluate strategic importance of bridges and tunnels considering seismic vulnerability: Application to Lisbon, in Proc., 2nd Euro Conference on Global Change and Catastrophe Risk Management: Earthquake Risks in Europe, 6-9 July 2000, Laxenburg, Austria [online], [cited 01 September 2013]. Available from Internet: http://www.iiasa.ac.at/Research/ RMS/july2000/papers.html.

Yashinsky, M.; Karshenas, M. J. 2003. Fundamentals of seismic protection for bridges. National Information Centre of Earthquake Engineering, Earthquake Engineering Research Institute.

Zanakis, S. H.; Solomon, A.; Wishart, N.; Dublish, S. 1998. Multi-attribute decision making: a simulation comparison of select methods, European Journal of Operational Research 107(3): 507-529. http://dx.doi.org/10.1016/S0377-2217(97)00147-1 
Ali YOUSEFI received his BSc degree from Azad University of Najafabad (2004) and MSc degree from Universiti Sains Malaysia (2013) in the field of Civil Engineering. Currently, he is pursuing his PhD at Universiti Sains Malaysia. His research interests include management and optimization of infrastructures performance, multi-criteria decision-making, structural health monitoring, risk mitigation, seismic retrofitting and nanofiber-reinforced concrete.

Mohd Sanusi S. AHAMAD earned his PhD degree from University of Nottingham, UK, in 1998 in the field of GIS. He is Currently an Associate Professor at the School of Civil Engineering, Universiti Sains Malaysia. He is author and co-author of more than 120 technical and scientific articles. His research interests are geo-spatial decisions, spatial site selections, and geomeasurement sciences.

Taksiah A. MAJID obtained her PhD degree in Structural Engineering from the University of Liverpool, UK, in 1996. Currently, she is an Associate Professor, the Deputy Dean (Academic) at the School of Civil Engineering and the Coordinator of the Disaster Research Nexus at the Universiti Sains Malaysia. Her research interests focus on numerical analysis of seismic engineering, wind engineering and industrialized building construction. 